This item was submitted to Loughborough's Research Repository by the author.

Items in Figshare are protected by copyright, with all rights reserved, unless otherwise indicated.

\title{
Remote-sensing disturbance detection index to identify spatio-temporal varying flood impact on crop production
}

PLEASE CITE THE PUBLISHED VERSION

https://doi.org/10.1016/j.agrformet.2019.02.002

PUBLISHER

(C) Elsevier

VERSION

AM (Accepted Manuscript)

\section{PUBLISHER STATEMENT}

This paper was accepted for publication in the journal Agricultural and Forest Meteorology and the definitive published version is available at https://doi.org/10.1016/j.agrformet.2019.02.002

LICENCE

CC BY-NC-ND 4.0

\section{REPOSITORY RECORD}

Chen, Huili, Qiuhua Liang, Zhongyao Liang, Yong Liu, and Shuguang Xie. 2019. "Remote-sensing Disturbance Detection Index to Identify Spatio-temporal Varying Flood Impact on Crop Production”. Loughborough University. https://hdl.handle.net/2134/37197. 


\title{
Remote-Sensing Disturbance Detection Index to Identify Spatio- Temporal Varying Flood Impact on Crop Production
}

\author{
Huili Chen ${ }^{1,2}$, Qiuhua Liang ${ }^{2}$, Zhongyao Liang ${ }^{1}$, Yong Liu ${ }^{1 *}$, Shuguang Xie ${ }^{1}$
}

1. College of Environmental Science and Engineering, Key Laboratory of Water and

Sediment Sciences (MOE), Peking University, Beijing 100871, China.

2. School of Architecture, Building and Civil Engineering, Loughborough University, UK

* Corresponding Author:

E-mail: yongliu@pku.edu.cn (Y. Liu); TEL: 8610 62753184; FAX: 861062751927. 


\section{ABSTRACT}

2 Flooding is the most common type of natural hazards that interrupt crop growth and reduce

3 production. Current understanding of flood impact on crops is largely obtained from broad-

4 scale studies without considering the influence of localized variations. Due to the highly

5 localized features of flooding, it is essential to develop an effective and systematic approach to

6 investigate and better understand the spatio-temporal varying flood disturbances at fine spatial

7 scales. Based on pixel-based time series of Enhanced Vegetation Index (EVI) data, two satellite-

8 based flood disturbance detection indices (DIs), i.e. EVI and peak EVI, are developed to

9 recognize the difference between the signals induced by natural variations and

10 instantaneous/non-instantaneous flood impact in crop growth processes. To define flood impact,

11 the actual and predicted normal values of temporal trajectories of EVI and peak EVI during the crop growing seasons are compared to detect and remove the interference from the crop's intraannual natural variations. A range of natural variations is considered to discern signal induced by the crop's inter-annual natural variations. Furthermore, recovery of crops from flooding is also considered by comparing the peak EVI during crop growing seasons to detect the final flood impact. Using the Northeast China as a case study area, we successfully demonstrate the capacity of these two DIs to identify spatio-temporal varying flood impact on crop production. The DIs also reveal positive response of crops to extreme precipitation under certain conditions. Further analysis demonstrates the non-linear relationships between flood disturbances and terrain slope, distance from rivers, and flow accumulation area, which enables the development of empirical regression models to sufficiently capture the variation of flood damage extent. The 
23 disturbances to crops and facilitating informed decision-making in agricultural flood 24 management.

25 KEYWORDS: Flooding; Crop Production; Enhanced Vegetation Index (EVI); Spatial 26 Characteristics; Positive Effect 


\section{INTRODUCTION}

It is widely recognized that climatic change has posed a great challenge to global environment and ecosystems in the 21 st century and beyond (Garcia et al., 2014; Seddon et al., 2016). The hydrological cycle is expected to intensify under global warming (Allen \& Ingram, 2002). Subsequently, extreme precipitation events will become more frequent in many regions of the world, leading to more natural hazardous events including flooding (Kadari et al., 2011; Schiermeier, 2011; Donat et al., 2016; Taylor et al., 2017; Zhu et al., 2017). Floods arising from intense rainfall may cause remarkable damage to crops, thus threatening local and global food security (Rosenzweig et al., 2002; Kenyon \& Shannon, 2008; Li et al., 2016; Yang et al., 2016;

Di et al., 2017; Shrestha et al., 2017).

Current understanding of crop response to flooding is largely obtained from broad-scale studies. For instance, Lesk et al. (2016) evaluated the impact of historical flood events on cereal production on a national basis across the globe. Similar studies have been undertaken at a national scale (Rosenzweig et al., 2002; Piao et al., 2014; Gourdji et al., 2015; Cobon et al., 2016), province/state scale (Pantaleoni et al., 2002; Lobell et al., 2011; Subash et al., 2011; Zhang et al., 2015; Yang et al., 2016; Zhang et al., 2016) and district level (Potopová et al., 2017; Shrestha et al., 2017). Most of these researches conclude that extreme precipitation and the resulting floods show various degrees of negative effects on agricultural production from the broad-scale perspective. The extreme precipitation, however, can potentially offset floodinduced damage by resolving the spatial and temporal discontinuity between water excess and water deficit (Brindha \& Pavelic, 2016). Floodwater harvesting through integrated water resources management has received significant attention in many regions across the globe ( $\mathrm{Li}$ 
et al., 2011; Eriyagama et al., 2014). Floodwater can be stored at the ground surface (e.g. reservoir) or in the subsurface (e.g. managed aquifer recharge) to provide irrigation supplies for agricultural productions (Moges, 2004; Pavelic et al., 2012; Saher et al., 2015), which may help mitigate the flood loss to a certain extent. So despite the fact that the attack of rainstorm or waterlogging more commonly causes crop failure, extreme precipitation may increase production of crops through alleviating water shortage under certain conditions. To the certain extent, the negative disturbances of floods may be offset or even surpassed by these positive effects across the whole area, which confirm the necessity of performing fine spatial scale studies to more comprehensively investigate and understand the flood impact on crop production.

Flood impact on crops may present clear temporal and spatial variations as influenced by localized weather and topographic conditions (Thornton et al., 2014; Lesk et al., 2016; Chen et al., 2017). The localized factors that influence flooding processes include precipitation, evaporation, topography, vegetation, soil, river streams, and flood control infrastructure (Merz et al., 2014). Hence, flood risk and impact on crops naturally exhibit high spatial heterogeneity due to the complicated interaction between these various localized factors. In recent years, many experimental attempts have been reported to investigate the crop response to waterlogging with controlled duration and depth, providing basic understanding of the morphology, physiology, yield, and recovery mechanisms for submerged crops (Xu et al., 2015; Arguello et al., 2016; Zhang et al., 2016; Wang et al., 2017). For effective flood risk assessment, however, it is challenging to extrapolate the laboratory findings to the real-world applications due to the scale effects and the lack of detailed spatial data revealing flood characteristics (Yang 
et al., 2017). Field survey has been a traditional approach to investigate flood impact on crop yield (e.g., Aryal et al., 2016). But this is a time-consuming and labor-intensive task, making it difficult, if not impossible, for large-scale applications. Considering its utter importance for disaster management and preparedness, a more effective and systematic approach must be developed to better understand the spatio-temporal characteristics of flood impact on crop production.

Remote sensing may often be the only feasible tool in terms of obtaining spatial and temporal field information to interpret flood dynamics (Haas et al., 2009; Ogilvie et al., 2015; Mohammadi et al., 2017). Inundation detection using remote sensing technologies has been a classical research topic in flood risk management. Different remotely sensed indices, which are usually related to moisture (e.g. open water, moist soil or vegetation water), have been developed to map flood areas or extents. In addition to detecting the flood extent, remote sensing also has a potential for effectively monitoring pixel-based spatial variation of crop growth conditions and yield at the local, regional, national and global scales (Beeri \& Peled, 2009; Beckerreshef et al., 2010; Alemu \& Henebry, 2013; Zhang \& Zhang, 2016). Based on the reflection characteristic of the green organs in crops, the vegetation index as derived from remote sensing has provided a potential means of indirectly estimating the stress status of crops (Jgpw \& Hjcvan, 1996; Franke \& Menz, 2007; Mohammadi et al., 2017). Thus, if remote sensing imagery with high revisit frequency and high image quality is available to derive a detailed time-series of images to capture the flood signals, it is feasible to effectively capture changes of crop growth vigor and biomass and hereby measure pixel-based crop responses to flooding over a large area. 
Two attempts have been reported to use the difference of vegetation index between the preflood and post-flood periods (Džubáková et al., 2015) or between the flood year and harvest year (Chen et al., 2017) to measure the flood damage extent. However, given that crops are usually shallow rooted and respond rapidly to hydrothermal variations, the magnitude of intraannual and inter-annual variations of vegetation greenness is relatively large in crop systems even without external disturbances (Zhang et al., 2003; Sakamoto et al., 2005). The difference of vegetation greenness between pre-flood and post-flood periods or between the flood year and harvest year may contain the signal representing crop's natural growth processes. It is therefore essential to distinguish the signals caused by natural variations and flood impact when detecting and defining flood disturbances. However, this has not been considered in the previous studies.

To fill the aforementioned gaps in research and application, the objective is to develop an effective and systematic approach to distinguish the signals caused by natural variations and flood impact, in order to investigate and better understand the spatio-temporal varying flood disturbances at fine spatial scales. Two satellite-based disturbance detection indices (DIs) are developed with an aim to acquire the spatial-temporal characteristics of instantaneous and noninstantaneous (integrated) flood impact on crop production on a pixel basis over a large scale. The DIs will be further used to explore and identify the key factors determining the crop loss induced by flooding. This will help identify and confirm those areas that are most vulnerable to flooding, and subsequently facilitate informed decision-making in flood risk mitigation and management at different levels. The proposed approach will be tested in the Northeast China, where the severe flood events in 2005 and 2013 have led to huge agricultural losses during the 
crop growing seasons.

\section{MATERIAL AND METHODS}

\subsection{Conceptual model for identifying flood impact on crop production}

Flooding affects crop production and it is one type of terrestrial disturbances that occurs outside the range of natural variations (Mildrexler et al., 2009). The priority for investigating the response of crops to flooding is to detect these disturbances. It is crucial to correctly identify the disturbances from the backdrop of natural variations when developing a disturbance index (Mildrexler et al., 2007). To enable systematic agricultural flood disturbance detection, two fundamental principles are applied: (1) crops, when left undisturbed, will achieve maximum vegetation greenness in a specified environment; and (2) flood disturbances will cause crops to have significantly different greenness. Vegetation indices have been widely used as a proxy of vegetation greenness for characterizing crop yield and net primary productivity (Shi et al., 2017). Although a number of different indices have been developed, the Normalized Difference Vegetation Index (NDVI) and the Enhanced Vegetation Index (EVI) are the most widely used indicators to monitor the conditions of different crops across the world (Son et al., 2014). More recently, EVI has been demonstrated to be more effective in monitoring crop growth than NDVI (Bernardes et al., 2012; Bolton \& Friedl, 2013; Zhang et al., 2014), due to fact that EVI is more sensitive to the variance in dense vegetation while NDVI becomes saturated (Rocha \& Shaver, 2009). EVI is computed using red, near infrared and blue reflectance bands with a practical range between 0 and 1. Absorption in the red band results in higher values of EVI. The index is strongly related to the chlorophyll content and photosynthetic activity and is suitable for 
monitoring crop growth dynamics (Huete et al., 2002). Therefore, EVI is adopted in this study and calculated by the following formula

$$
\mathrm{EVI}=2.5 \times\left(\mathrm{R}_{\mathrm{Nir}}-\mathrm{R}_{\mathrm{Red}}\right) /\left(\mathrm{R}_{\mathrm{Nir}}+6 \times \mathrm{R}_{\mathrm{Red}^{-}}-7.5 \times \mathrm{R}_{\text {Blue }}+1\right)
$$

where $R_{N i r}$, $R_{R e d}$ and $R_{B l u e}$ refer to the reflectance of the near-infrared, red and blue bands of remote sensing images, respectively.

The processes of flooding disturb crop growth at a rate different from a range of natural growth variations and subsequently have different impact on crop production. Instantaneous disturbances caused by flash floods with high flow velocity may result in an abrupt deviation from the vegetation index featuring natural growth processes. The vegetation index following prolonged disturbances from those flood events caused by e.g. continuous "plum rains" often deviates incrementally and returns slowly to the normal conditions (crop recovery) after the wet stress finishes. These features imply the necessity for a multi-pronged approach to flood disturbance detection. Both of these instantaneous and non-instantaneous responses can be effectively detected by tracking temporal trajectory of the vegetation index during the crop growing seasons. The non-instantaneous response of crop yield can be surrogated by the vegetation index reflecting peak greenness. The maximum vegetation index of crops has been demonstrated to be the most effective indictor in predicting crop yield (Rasmussen, 1992; Groten, 1993; Bolton \& Friedl, 2013; Rembold et al., 2013; Zhang \& Zhang 2016; Duan et al., 2017). Thus crop yield loss may be evaluated through analyzing the characteristics of the peak vegetation index of crops.

Given that the magnitude of intra-annual and inter-annual variations of vegetation greenness is relatively large in crop systems even without external disturbances, it is essential to detect 
and remove the natural variations of crops when developing a disturbance detection index. In order to avoid the possible high intra-annual change associated with the dynamic but natural crop growth possesses during the crop growing seasons, we compare the actual and predicted normal values of EVI. The time-series of the EVI and peak EVI during the crop growing seasons are used to track the instantaneous and non-instantaneous (integrated) effects, respectively. Here, the time-series of the EVI mean the maximum value of the EVI for a certain period (16 days used in this study). Thus, the instantaneous variant of the disturbance index $\left(\mathrm{DI}_{\mathrm{i} \_ \text {Inst }}\right)$ and the integrated disturbance index $\left(\mathrm{DI}_{\text {Inte }}\right)$ are defined as follows:

$$
\mathrm{DI}_{\mathrm{i}_{-} \text {Inst }}=\mathrm{VI}_{\mathrm{i}} / \mathrm{VI}_{\mathrm{i}_{-} n o}
$$

$$
\mathrm{DI}_{\text {Inte }}=\mathrm{VI}_{\text {max }} / \mathrm{VI}_{\text {max } \_ \text {no }}
$$

where $\mathrm{i}$ represents the time period during a crop growing season, $\mathrm{VI}_{\mathrm{i}}$ is the actual EVI during period $\mathrm{i}, \mathrm{VI}_{\mathrm{i}_{-} n o}$ is the predicted normal EVI without external disturbances during period $\mathrm{i}$, $\mathrm{VI}_{\text {max }}$ is the actual peak EVI during a crop growing season, and $\mathrm{VI}_{\text {max } \_n}$ is the predicted normal peak EVI without external disturbances during a crop growing season.

Detecting and quantifying flood impacts is challenging because crop production is influenced by many factors, including weather and climate factors, as well as technological advances. The overall trend of EVI and yield is increasing, which is mainly caused by technological advances; the fluctuations are mainly controlled by weather and climate factors ( $\mathrm{Lu}$ et al., 2017). Quantifying flood impacts on crop growth needs to know the long-term EVI trend caused by technological factors. This study adopts a linear regression model to identify the long-term trend without external disturbances and acquire the expected normal crop EVI influenced only by technological factors. Afterwards, the actual crop EVIs and the expected ones are compared 
to detect out a meaningful flooding effect on crop growth.

$$
Y_{t}=\beta_{0}+\beta_{1} t
$$

where $Y_{t}$ is the crop EVI at year $\mathrm{t}$, year $\mathrm{t}$ is the independent variable, and $\beta_{0}$ and $\beta_{1}$ are the coefficients.

$\mathrm{VI}_{\mathrm{i}_{\_} \text {no }}$ and $\mathrm{VI}_{\text {max } \_ \text {no }}$ in Eq. (2) and Eq. (3) can be derived from the predicted values of the time-series of the EVI and peak EVI, which are obtained from their respective regression-based models. Eq. (2) and Eq. (3) are also presented in the conceptual model as illustrated in Fig. 1. The disturbance indices (DIs) are dimensionless parameters defined as the ratio of the vegetation indices between the current year and historical normal years. If a given pixel is not disturbed, DIs tend to have a value of 1.0. However, since the growth conditions of a cropland are typically not static, DIs will vary within the range defined by the natural variations (indicated by the shadowed grey area in Fig. 1), even without external disturbances. When a flash flood event occurs, the vegetation index in the affected area will decrease instantaneously to a value that is obviously less than the multi-year mean. The negative effects induced by the flood event (as shown in red in Fig. 1a) will be detected since it shifts outside the range of natural variations. As the affected area recovers from the flood impact, indicated by increasing vegetation index, the bi-directional nature of DIs will track the incremental change toward recovery and the DI values will again fall inside the range of natural variations. Similarly, the positive effects from extreme precipitation (as shown in blue in Fig. 1a, larger than the multiyear mean) will also be detected when the signal shifts outside the range of natural variations. 

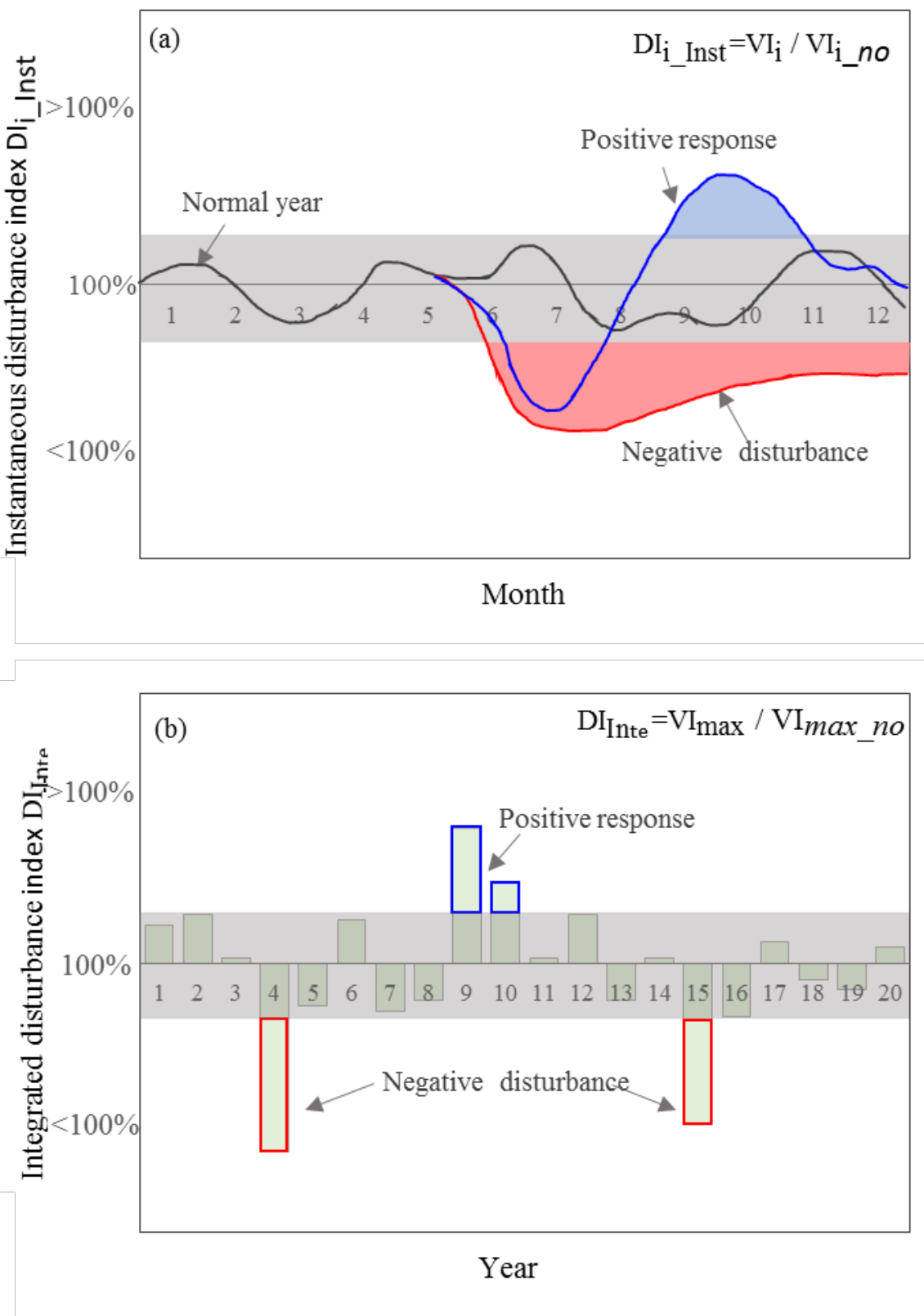

Fig. 1. The DIs algorithm and conceptual model illustrating the flood disturbance on

crop production. The upper panel is for the instantaneous disturbance index and the lower

natural variation. 


\subsection{Ridge regression model for identifying influential factors controlling flood damage} extent on crop yields

After successfully detecting flood disturbances using the integrated DI index, the damaged degree (DD, define as $1-\mathrm{DI}_{\text {Inte }}$ ) can be obtained for every negatively disturbed pixel whose $\mathrm{DI}_{\text {Inte }}$ distributes outside the range of natural variations. Herein, the influential factors controlling the damaged extent on crop production are investigated and discussed. These factors may include flow accumulation area (F), terrain slope (S) and distance from river stream (D), which have been verified as the three dominant parameters in assessment of flood risk (Kazakis et al., 2015). The detailed introduction on these three factors can be seen in Supporting Material. The relationships between these three influential factors and the yield damaged degree are established respectively through analysis of data distributions. To examine the interactive effects of the influential factors on the flood damage extent, the data are further analyzed using a ridge regression model, which is chosen because of the possible existence of collinearity in the variables. Ridge regression has been widely used to handle collinearity in multivariate regression by penalizing the size of the regression coefficients (Hoerl \& Kennard, 1970). Ridge regression sacrifice a little bias for large reductions in the variance of the predicted values (Simpsona \& Montgomery, 1996). The standard error of the estimated regression coefficients is smaller than that of the ordinary least squares, providing estimated results that are more stable and closer to the true values. The detailed introduction on Ridge regression can be seen in Supporting Material. In this study, the ridge regression model is performed using the ridge package in R. 


\subsection{Study area and events}

Northeast China (including Heilongjiang, Jilin, and Liaoning provinces) is one of the most important grain producing areas in China (Fig. 2). The region has a total area of approximately 0.79 million square kilometers, with longitude extending from $120^{\circ} \mathrm{E}$ to $135^{\circ} \mathrm{E}$ and latitude spanning from $38^{\circ} \mathrm{N}$ to $53^{\circ} \mathrm{N}$. In the Northeast China, $45.46 \%$ of the total area is planted with crops (Cong et al., 2017). The crop systems mainly include corn, rice, and soybean and are typically featured with single-cropping every year (Chen et al., 2012). These crops are sown in late April and harvested by the end of September. The landscape is dominated by mountains and plains, with the Changbai Mountain in the eastern fringe, Lesser Khingan Mountains to the north and Great Khingan Mountains to the west. The Sanjiang, Songnen and Liaohe plains, distributed from the north to the south, house most of the farmlands in the Northeast China, which are famous for rich soil. The region is dominated by a continental monsoon climate and the annual rainy seasons (July to September) overlap with the crop-growing seasons (April to September). Therefore, the plain areas along the middle and lower reaches of the major rivers are particularly vulnerable to flooding, which may adversely affect crop production (Yang et al., 2007). 

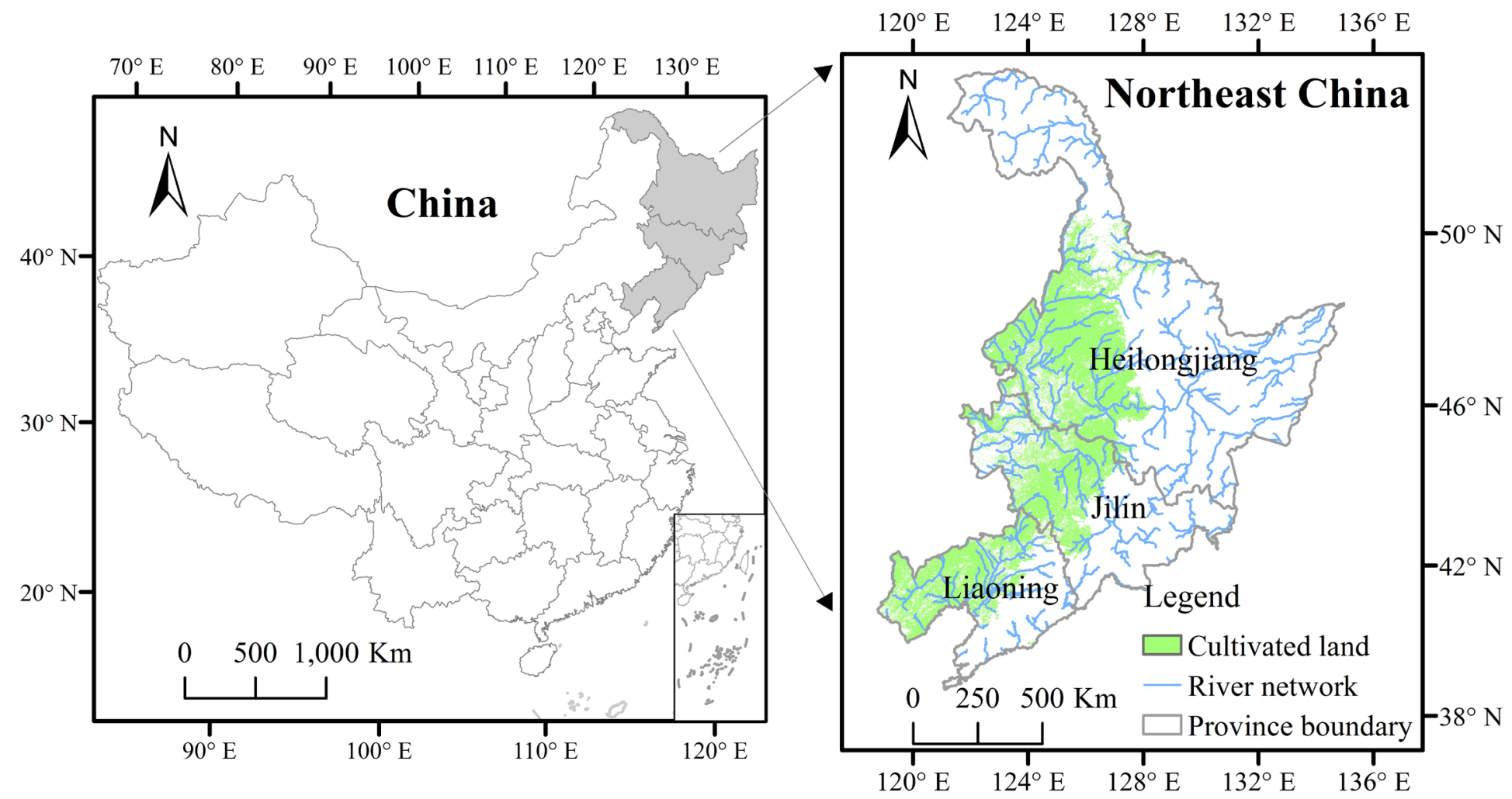

Fig. 2. The study area. The left panel shows the position of the study area (Northeast China) in China. The right panel shows the spatial distribution of

cultivated land in Northeast China. 
Fig. 3, the annual average crop area affected by flooding is $9584 \mathrm{~km}^{2}$ (approximately $5.4 \%$ of

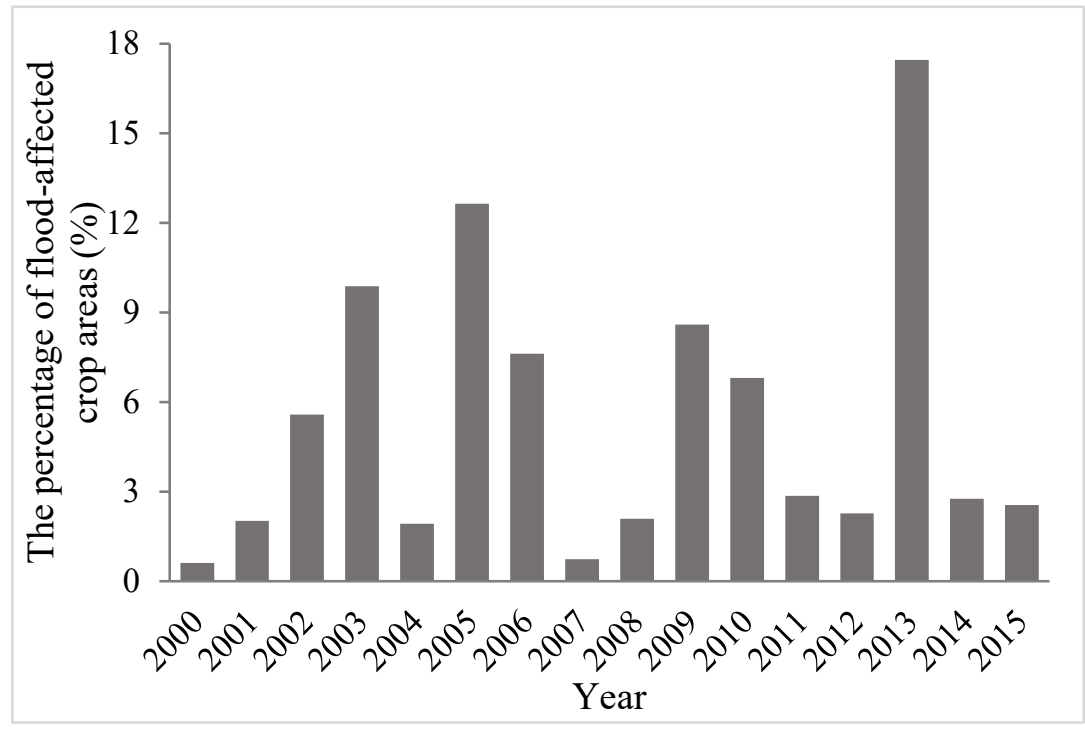

Fig. 3. The percentage of flood-affected crop areas among the total cropland area in the of China. 


\subsection{Data Acquisition}

The Moderate Resolution Imaging Spectroradiometer (MODIS), with its high frequent sampling (twice-daily) and relatively long data archive (since 2000 to now) across the globe, provides a unique dataset to explore crop response to flooding. However, frequent interference of clouds during the rainy days makes it difficult to acquire a daily series of flood images over a single flood event. Thus the 16-day MOD13Q1 version 6 product is used, which comprises the 16-day, global enhanced vegetation index (EVI) at $250 \mathrm{~m}$ resolution for the period from 2000 to 2016 (Didan et al., 2015). The MOD13Q1 version 6 product is provided by the NASA Earth Observing System (EOS) (ftp://ladsweb.nascom.nasa.gov/allData/6/, Didan, 2015). The 16-day product is a maximum value composite (MVC), which selects the least cloudatmosphere contaminated pixels and also tends to select the closest near-nadir view (Huete et al., 1999). The MOD13Q1 reliability layer is used to remove all unreliable pixels (value $>1$ ) before DIs are calculated.

The cropland area is obtained from the GlobCover 2009 dataset with $300 \mathrm{~m}$ resolution for the period between January and December 2009, which is developed from the Medium Resolution Imaging Spectrometer (MERIS) data and provided by the European Space Agency (Arino et al., 2012). According to Liu et al. (2014), croplands in the Northeast China significantly increased from late 1980s to 2000 mainly due to the reclamation of forests, grasslands, and unused lands, but the croplands remained almost unchanged after 2000. Thus, the cropland area obtained in 2009 is used in the current study, covering the period between 2000 and 2016. Also this study adopts the Shuttle Radar Topographic Mission (SRTM) digital elevation model (DEM) data, which has a spatial resolution of $90 \mathrm{~m}$ (Farr et al., 2007). River networks and flow 
accumulation maps with a 15 Arc-Second resolution are extracted from the HydroSHEDS datasets (Lehner et al., 2008). The GlobCover 2009 data, DEM and flow accumulation maps are resampled into a pixel size of $250 \mathrm{~m} \times 250 \mathrm{~m}$ using the nearest neighbor algorithm in order to match the spatial resolution of the MODIS EVI product. Daily precipitation data from 133 meteorological stations is obtained from the National Climate Center (NCC) of the China Meteorological Administration (CMA), which is used for forcing two-dimensional hydraulic model combined with the SCS-CN hydrological model to accomplish the flood simulation and the spatial and temporal quantification of flood parameter (see Supporting Material Methods). Additionally, the provincial flood-affected crop areas for the period from 2000 to 2015 are collected from the National Bureau of Statistics of China. Herein, the flood-affected crop areas are defined as the agricultural lands with more than $10 \%$ of the expected crop yield being affected by floods (Zhang et al., 2016). Any flood-impacted cropland areas with crop yield loss above $10 \%$ will be recorded in disaster dataset at the provincial scale. City-level crop yield statistics in Northeast China from 2001 to 2013 are collected from the data collection website (http://www.soshoo.com.cn/index.do).

\section{RESULTS}

\subsection{Spatial Characteristics of Flood Disturbances on Crop Production}

The relationship between the peak EVI and crop yield is first investigated, which is the foundation of computing the DIs. The peak EVI in each year derived from multi-temporal MODIS imagery in association with crop yield data are used to develop empirical models for each city to corroborate the subsequent analysis based on peak EVI. From the results (see 
303

304

305

306

307

308

309

310

311

312

313

Supporting Material Fig. S1), the peak EVI has a significant linear correlation with the crop yield in 19 of 22 cities. There are no significant correlations in Jilin City, Changchun City and Panjin City. On the whole, the results of the linear models based on peak EVI can sufficiently capture the yearly crop yield variation in Northeast China. Subsequently, the DIs are computed from the MODIS MOD13Q1 data during the crop growing seasons (April to September) for the period from 2000 to 2016 across the whole Northeast China.

Fig. 4 presents the 2005 and 2013 integrated $\mathrm{DI}\left(\mathrm{DI}_{\text {Inte }}\right)$ across the cultivated lands of the Northeast China. The flood-disturbed areas detected by the $\mathrm{DI}_{\text {Inte }}$ are verified against the official statistics released by the government (Table 1). As mentioned before, the growth conditions of the croplands will vary within a natural variation range even without external disturbances. The standard deviation from the $\mathrm{DI}_{\text {Inte }}$ of normal years without disturbances can be used to define the natural variation range (Mildrexler et al., 2009). In the current case study, it is found that one standard deviation of $\mathrm{DI}_{\text {Inte }}$ is within $10 \%$ of the mean in $91 \%$ of the entire agricultural area under consideration. Meanwhile, the National Bureau of Statistics of China adopts $10 \%$ loss of the expected crop yield as the threshold for flood damage. Any crop areas with flood loss above the threshold are recorded in the Bureau's disaster dataset. Thus, we define the natural variation range as \pm 0.1 of the mean without external disturbances (i.e., 0.91.1). Therefore, croplands with $\mathrm{DI}_{\text {Inte }}$ less than 0.9 are considered to be negatively disturbed by flooding. Based on this criterion, $11,751 \mathrm{~km}^{2}$ and $25,350 \mathrm{~km}^{2}$ of croplands across Heilongjiang are detected to be respectively impacted by the 2005 and 2013 floods using the $\mathrm{DI}_{\text {Inte, }}$, which are very close to flood-affected area statistics released by the government. The detected disturbed areas also agree well with the flood-affected area statistics in Liaoning and 
Jilin, although where the flooding damage was not as serious as that in Heilongiiang. As a whole, the errors between the detected areas and the official statistics are less than $15 \%$ for all three Northeast provinces.

Besides, we use the two-dimensional hydraulic model coupled with the SCS-CN hydrological model to simulate the spatiotemporal dynamics of flood evolution over the upstream watershed of Songhua River. The upstream watershed of Songhua River occupies $70 \%$ of the cultivated land in the Northeast China and is used as the computational domain (see Supporting Material Fig S2). The detail of the two-dimensional hydraulic model and the SCS-CN hydrological model can be seen in supporting material. The simulation results are shown in Fig S2. According to the simulation results, $78 \%$ and $69 \%$ of the watershed areas were inundated with water depth over $10 \mathrm{~mm}$ in 2005 and 2013, respectively. Combining the flood disturbance results based on remote sensing imagery and flood simulation via hydraulic modeling, the disturbance condition and flood characteristics can be gained detailedly for every cell. Then we counted the distribution of maximum water depth for these negatively disturbed pixels within the watershed (Table S2). According to the count results, $92.9 \%$ and $83.9 \%$ of these negatively disturbed pixels were inundated with water depth over $10 \mathrm{~mm}$ in 2005 and 2013, respectively. And $81.4 \%$ and $70.1 \%$ of them were inundated with water depth over $50 \mathrm{~mm}$ in 2005 and 2013 , respectively. Thus, the vast majority of these negatively disturbed pixels were indeed hit by devastating floods. And given the external disturbances to the crops were dominated by flooding in these two years. The results indirectly indicated that our disturbance results are reliable and the flood disturbance can be effectively detected using the proposed $\mathrm{DI}_{\text {Inte }}$. 


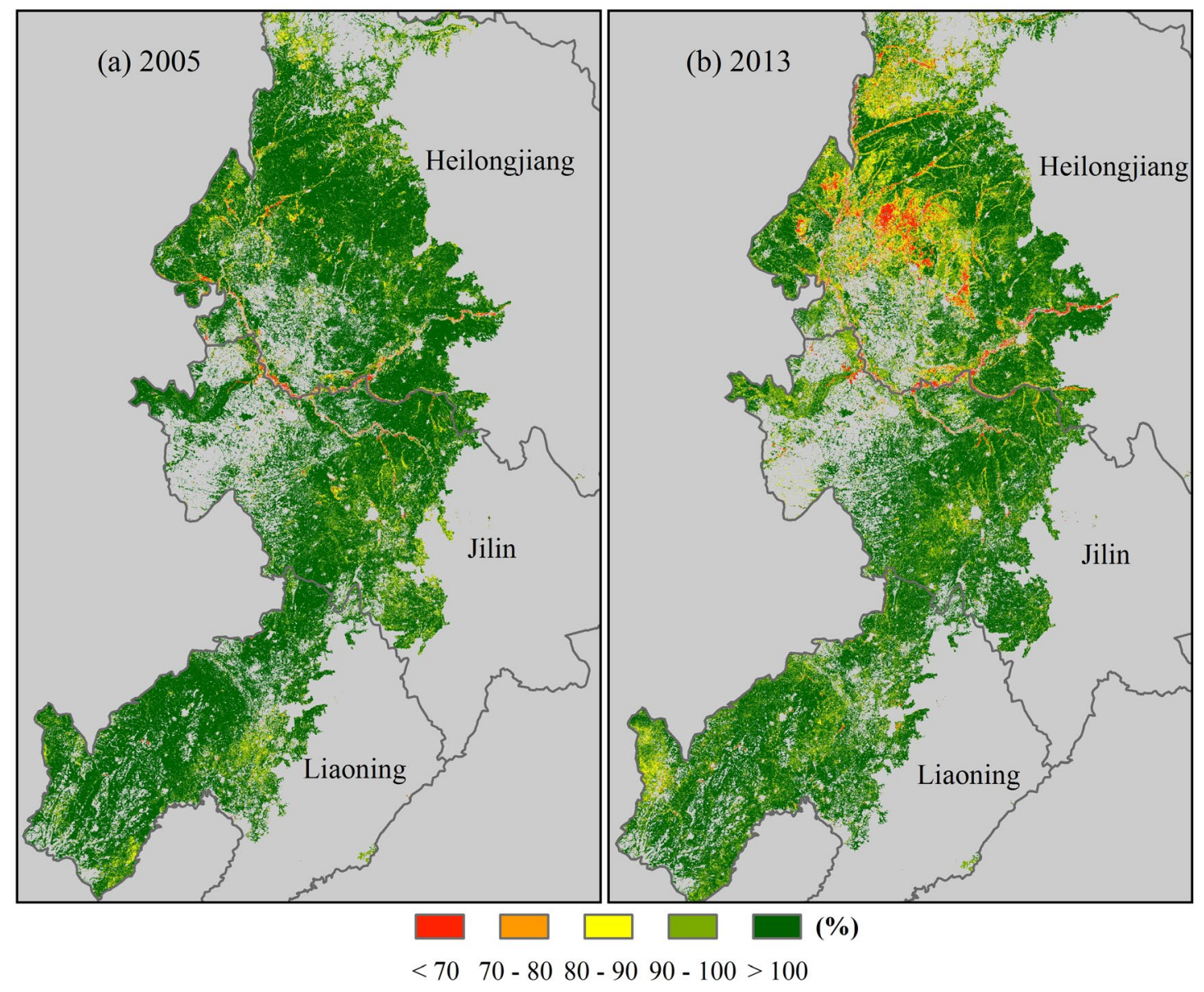

Fig. 4. Flood disturbance detection results obtained from the integrated DIs based on the comparison between the actual peak EVI and predicted normal peak EVI in the

Northeast China. The left panel shows the result of year 2005. The right panel shows the 


\begin{tabular}{ccccccc}
\hline \multirow{2}{*}{ Province } & \multicolumn{3}{c}{ Year 2005 $\left(\mathrm{km}^{2}\right)$} & \multicolumn{3}{c}{ Year 2013 $\left(\mathrm{km}^{2}\right)$} \\
\cline { 2 - 7 } & Statistics & Remote sensing & Error (\%) & Statistics & Remote sensing & Error (\%) \\
\hline Heilongjiang & 13146 & 11751 & -10.61 & 26553 & 25350 & -4.53 \\
Jilin & 3645 & 3554 & -2.50 & 4273 & 4338 & 1.52 \\
Liaoning & 3447 & 3374 & -2.12 & 3363 & 3631 & 7.97 \\
Total & 20237 & 18679 & -7.70 & 34189 & 33319 & -2.54 \\
\hline
\end{tabular}

In addition to compare with the statistical data, the spatial characteristics of the negatively

355 disturbed croplands have also been investigated. According to Garssen et al. (2015), Akbari et evaluate the results, the distance from these negatively disturbed pixels to their nearest rivers is river streams within $1700 \mathrm{~m}$ is closely correlated with flood impacts. Through analysis of the 
371 potential flood-prone areas, as expected. This indirectly validates the detected flood-disturbed

372 areas and also the effectiveness of the $\mathrm{DI}_{\text {Inte }}$ developed in this study for flood disturbance

373 detection.

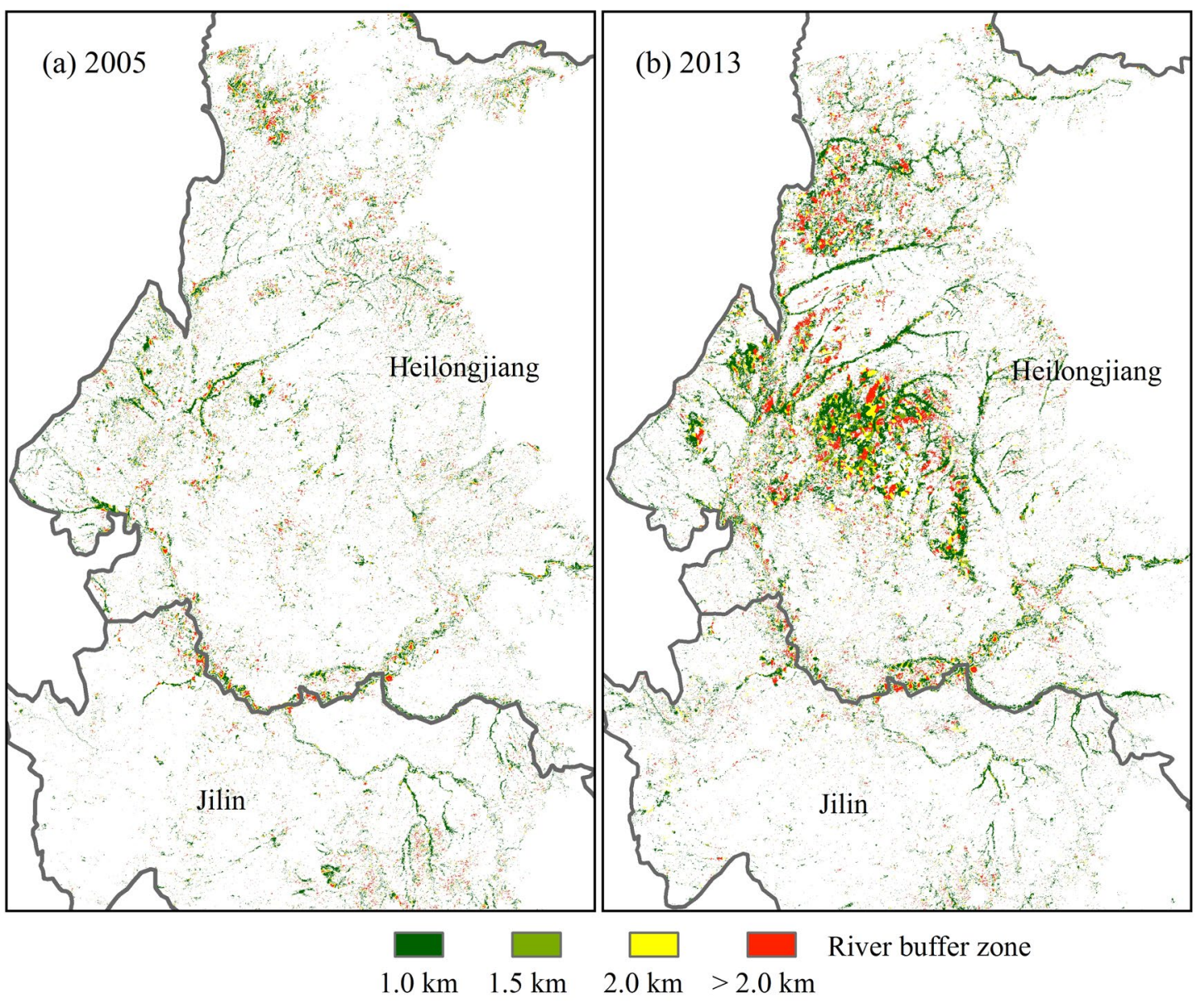

Fig. 5. Spatial distribution of crop areas negatively disturbed by floods in the floodplains in the Songnen plain. The color represents the distance to the nearest river.

Table 2. Percentage of crop areas disturbed by floods within a certain range to the nearest river $(\%)$.

\begin{tabular}{ccccccc}
\hline Distance $(\mathrm{m})$ & 200 & 500 & 1000 & 1500 & 2000 & 3000 \\
\hline Year 2005 & 14 & 31 & 52 & 68 & 79 & 93 \\
Year 2013 & 14 & 32 & 53 & 68 & 80 & 94 \\
\hline
\end{tabular}

In addition to the negative disturbances from flooding, the positive response of the peak EVI 
381

382

in the detection results as shown in Fig. 4. $21.7 \%$ and $6.8 \%$ of the cultivated lands showed positive response of the peak greenness with $\mathrm{DI}_{\text {Inte }}$ greater than 1.15 in 2003 and 2015 , respectively. We counted the distribution of maximum water depth for these pixels with positive response within the watershed (see Supporting Material Table S1). According to the results, $95.1 \%$ and $88.5 \%$ of these pixels were inundated with water depth over $5 \mathrm{~mm}$ by the 2005 and 2013 floods, respectively. However, only 59.1\% and $43.8 \%$ of them were inundated with water depth over $50 \mathrm{~mm}$. Thus, the vast majority of these pixels with positive response happened where water flow came into being or went through while water flow was shallow. Traditionally, it is widely recognized that extreme precipitation events have negative effects (e.g., Kent \& Johnson, 2001; Samantaray et al., 2015; Kotera et al., 2016), or no obvious effects (Pantaleoni et al., 2007; Lesk et al., 2016) on crop production. The detected positive response of the peak greenness to extreme precipitation events in some specific areas have not been previously investigated and analyzed. We infer that the main reason for this inconsistence is that the previous studies tend to treat the affected areas as a single entity and focus only on total flood effects in the affected areas without considering localized spatial variations. In the current study, we investigate the flood response for individual fields (i.e., every $250 \mathrm{~m}$ x $250 \mathrm{~m}$ pixel) within the whole watershed to take into account spatial variations. Whilst being a major type of nature hazards leading to loss of crop production in the damaged areas, extreme precipitation events may also have positive results, at least locally, in terms of increasing the availability of water resources or increasing soil moisture, which is favorable for crop growth under certain conditions. This will be further analyzed and verified in next section. 
Using the instantaneous DI as introduced in Section 2.1, a time series of 16-day composite

$404 \mathrm{DI}_{\mathrm{i} \text { Inst }}$ during the crop growth seasons in the Northeast China can be produced to provide 405 information on crop growth changes before and after flooding. The crop growth season is derived from the cropping calendar (http://zzys.agri.gov.cn/nongshi.aspx). In this section, the year of 2005 is taken as an example to facilitate further analysis and discussion of the temporal characteristics of flood disturbances. According to the China National Commission for Disaster Reduction, two extremely flood events happened in the Northeast China in 2005. A rainstorm hit the central south Heilongjiang on $27^{\text {th }}$ July 2005 (China National Commission for Disaster

411 Reduction, 2005a), followed by another extreme flood event between $10^{\text {th }}$ and $14^{\text {th }}$ August, 412 which caused disastrous consequences for agriculture in all three Northeast provinces of China 413 (China National Commission for Disaster Reduction, 2005b). DI $\mathrm{I}_{\mathrm{i} \text { Inst }}$ is calculated for period 414193 (the $193^{\text {rd }}$ day to $208^{\text {th }}$ day, and before these two flood events) and 209 (the $209^{\text {th }}$ day to $415224^{\text {th }}$ day, and after the first event and during the second event) of the year from the MODIS 416 16-day composite, as presented in Fig. 6a-b. The instantaneous DI is observed to decrease in 417 most of the areas. However, in the northern regions (i.e., Songnen plain), the instantaneous DI increases after flooding. 


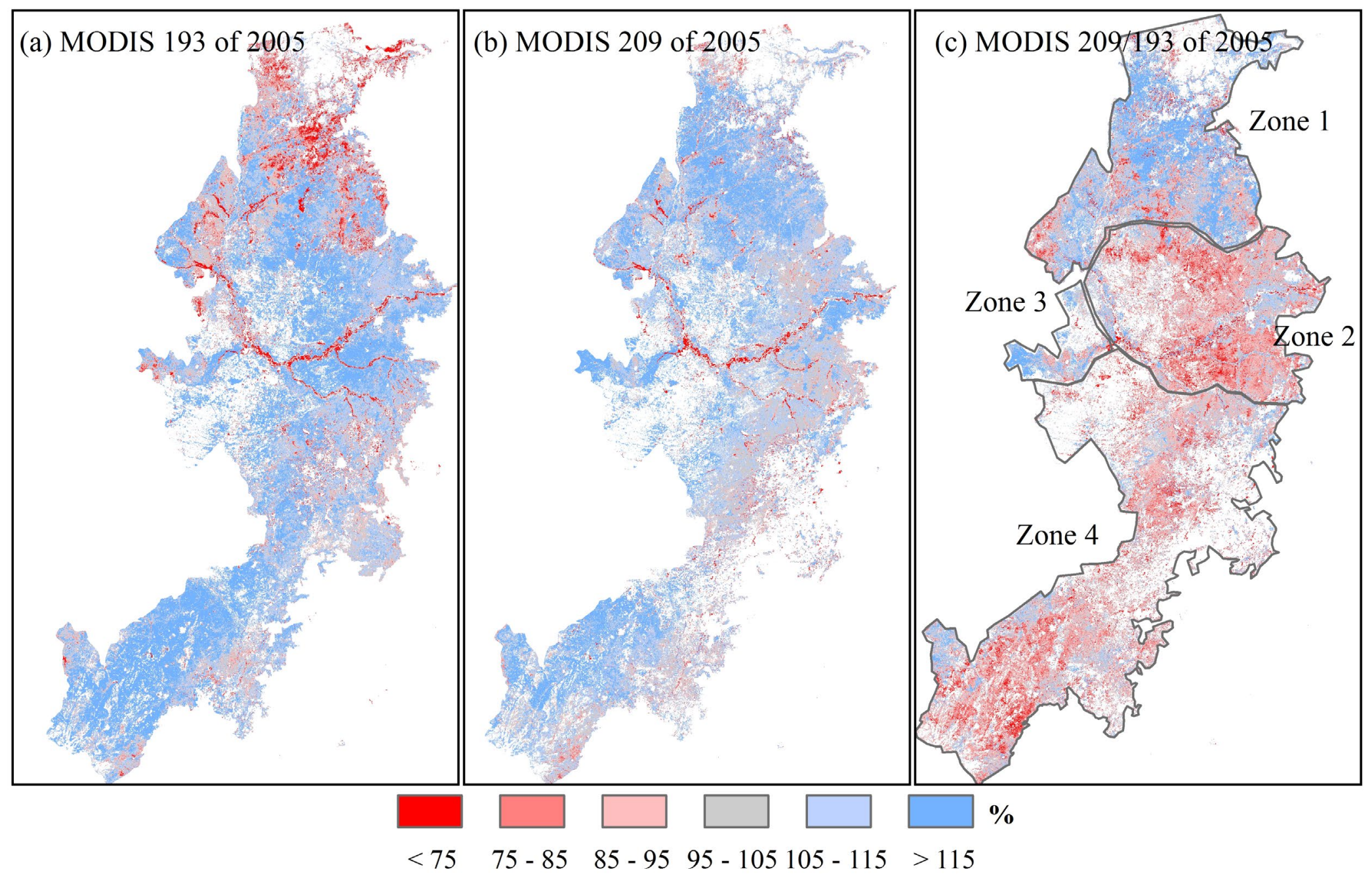

Fig. 6. Flood disturbance detection results obtained from the instantaneous DIs based on the actual EVI and predicted EVI during the same period

in the Northeast China. The left panel shows the result of period 193 (the $193^{\text {rd }}$ day to $208^{\text {th }}$ day) in 2005 . The middle panel shows the result of period 209 
(the $209^{\text {th }}$ day to $224^{\text {th }}$ day) in 2005 . The right panel shows the ratio between the result of period 209 and that of period 193 in 2005 . 
423

424

425

426

427

Comparison of results between the flooding and non-flooding periods, i.e., the ratio between the result of period 209 and that of period 193, helps to more explicitly recognize the crop's direct response to flooding. Fig. $6 \mathrm{c}$ shows the ratio of $\mathrm{DI}_{\mathrm{i}_{-} \text {Inst }}$ after and before flooding, i.e., $\mathrm{DI}_{209}$ Inst to $\mathrm{DI}_{193 \text { _nnst }}$. As illustrated in Fig. 6c, the response of crop growth to flooding presents obvious spatial pattern across the floodplain. In order to facilitate the analysis, the floodplain is divided into four zones, according to different floodplain responses. There are $71.0 \%$ and $67.8 \%$ of the pixels with decreased instantaneous DI in zone 2 and zone 4 , respectively. The decreased instantaneous DI indicates that flooding causes negative impact on crop growth. In both zones, flooding hinders crop growth and subsequently reduces vigor of the crops. Zone 1 is mainly located in the Midwest of Heilongjiang with $68.7 \%$ pixels having increasing instantaneous DI. Zone 3 shares similar characteristics with zone 1 with $66.0 \%$ pixels having increasing instantaneous DI. Although the maximum daily rainfall in certain stations in zone 1 and zone 3 is recorded to be as high as $30 \mathrm{~mm}$ or over, crops are shown to grow better during and after flooding in most areas, except for the riparian zones around rivers.

To further analyze the reasons, it is found that Heilongjiang experienced higher temperature and drier weather than usual from January to June in 2005, causing severe drought in the whole province (Xiao \& Xu, 2006). Subsequently, the crops were negatively disturbed by droughts, with $26 \%$ of the pixels having $\mathrm{DI}_{193}$ _Inst (corresponding to July) less than 0.9 in zone 1 . With the increased rainfall in July, the drought had been eased, as demonstrated by less negatively disturbed pixels in $\mathrm{DI}_{209}$ Inst , leading to positive flood impacts.

\subsection{Influential Factors Controlling the Flood Damage Extent on Crop Yields}

After successfully using the integrated DI index to identify flood disturbances, the damaged 
degree (DD, define as $1-\mathrm{DI}_{\text {Inte }}$ ) can be obtained for every negatively disturbed pixel with $\mathrm{DI}_{\text {Inte }}<0.9$. Herein, the influential factors controlling the damaged extent on crop yield are investigated and discussed. The average values of influential factors are calculated for those pixels with the same yield damaged degree, i.e. the average values of the three factors (including terrain slope, distance from rivers, and flow accumulation area) against every $1 \%$ yield loss ratio. Flow accumulation area is defined as the upstream area draining into the pixel(s) under consideration, which is extracted from the HydroSHEDS datasets. Slope is topographic slope and is calculated based on DEM in ArcGIS. The distance from rivers is defined as the distance of the pixel to its nearest river stream, which is calculated in ArcGIS. In total 90 groups (from $10 \%$ to $99 \%$ at a $1 \%$ interval) of data are selected. The relationships between the three influential factors and the yield damaged degree are established respectively according to the data distributions and illustrated in Fig. 7. These relationships are not linear and may lead to several interesting conclusions. Firstly, in Fig. 7a and Fig. 7b, it is shown that all serious damages with a damaged degree $>40 \%$ (indicated by red points) happen in locations with a terrain slope less than $0.40^{\circ}$. This implies that only the crops in those areas with a slope less than $0.40^{\circ}$ may experience amplified responses to flood disturbances and $0.40^{\circ}$ may be defined as the critical terrain slope to trigger serious flood-induced crop failure in the Northeast China. The reason may be that, in the landscapes with a terrain slope less than $0.40^{\circ}$, the driving force, i.e. gravity, to move the floodwater to downstream becomes critically small and the floodwater accumulates to form serious waterlogging during a flood event. Secondly, as indicted in Fig. $7 \mathrm{a}-\mathrm{b}$, the damaged degree is highly and linearly correlated with the slope $\left(\mathrm{R}^{2} \geqslant 0.94\right)$ when the damaged degree is below $40 \%$. Once it exceeds the threshold of $40 \%$, the damaged degree 
467 almost has no correlation with the slope. Thus for the moderate damage state, lower terrain 468 slope leads to more serious crop damage. Finally, from Fig. 7c-f, the damaged degree is 469 positively related to the flow accumulation area and negatively to the distance from stream, as 470 it is expected. 

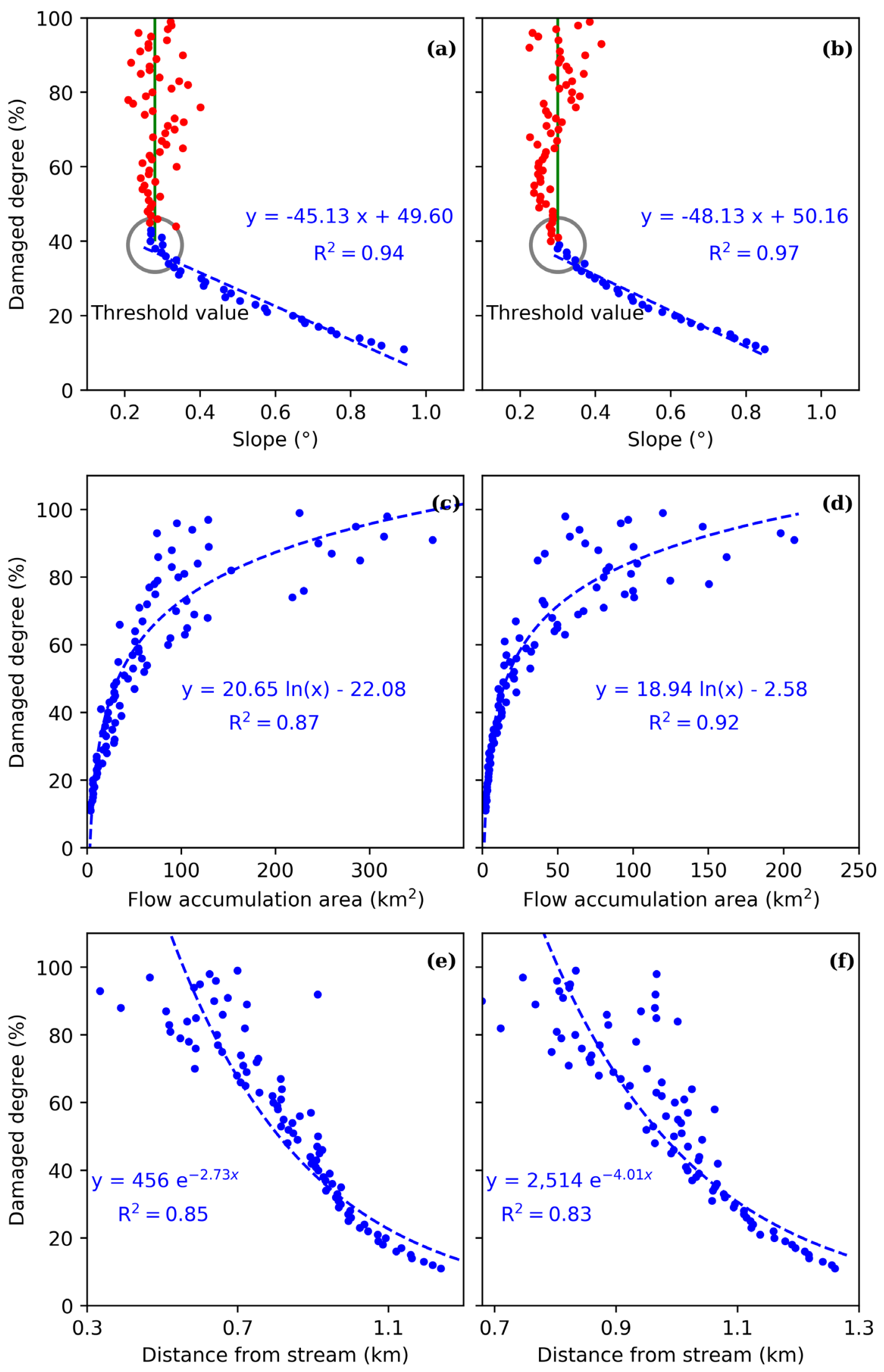

Fig. 7. The relationship between the influential factors and crop damaged degree in the 
473 Northeast China. The relationship is measured using the regression equation with maximum coefficients of determination $\left(\mathrm{R}^{2}\right)$. The left panel is obtained for 2005 and the right panel for 2013.

The data are further analyzed to examine the interactive effects of the influential factors on the flood damage extent. Pearson's correlation coefficient (r) between the slope and the flow accumulation area is -0.38 and -0.33 for year 2005 and 2013, respectively. The $r$ between the slope and the distance from river stream is -0.61 and -0.75 for year 2005 and 2013, respectively. The $r$ between the distance from river stream and the flow accumulation area is 0.70 and 0.68 for year 2005 and 2013, respectively. The condition index is 17.35 and 40.22 for year 2005 and 2013, respectively. If the condition index is 15 , multicollinearity is a concern; if it is $>30$, multicollinearity is a very serious concern (Midi et al., 2010). Thus, a ridge regression model is used due to the collinearity in the influential factors. Given the nonlinear relationships between the influential factors and the damaged extent (Fig. 7), the ridge regression model is built using the natural logarithm of the current values. The regression equations are developed for the 2005 and 2013 events respectively as follows:

$$
\begin{aligned}
& \operatorname{Ln}(D D)=8.28-0.44 \operatorname{Ln}(S)-0.61 \operatorname{Ln}(D)+0.26 \operatorname{Ln}(F) \\
& \operatorname{Ln}(D D)=9.22-0.50 \operatorname{Ln}(S)-0.68 \operatorname{Ln}(D)+0.27 \operatorname{Ln}(F)
\end{aligned}
$$

where $\mathrm{DD}$ is the damaged degree in $\%$; $\mathrm{S}$ is the slope in minutes; $\mathrm{D}$ is the distance from river stream in meters; and $\mathrm{F}$ is the flow accumulation area in square kilometers.

All estimated coefficients pass the significance tests with a t-statistic above the significance level of 0.05 . The ridge regression estimate clearly shows that the damaged extent increases with reduced slope (S) and distance from river stream (D) and increased flow accumulation 
area (F). The actual and model predicted damages are compared and showed in Fig. 8. Most of the data points are in close proximity to the $1: 1$ line, which indicates that the empirical regression model based on the three variables may sufficiently capture the varying extent of flood damage on crops across the Northeast China.
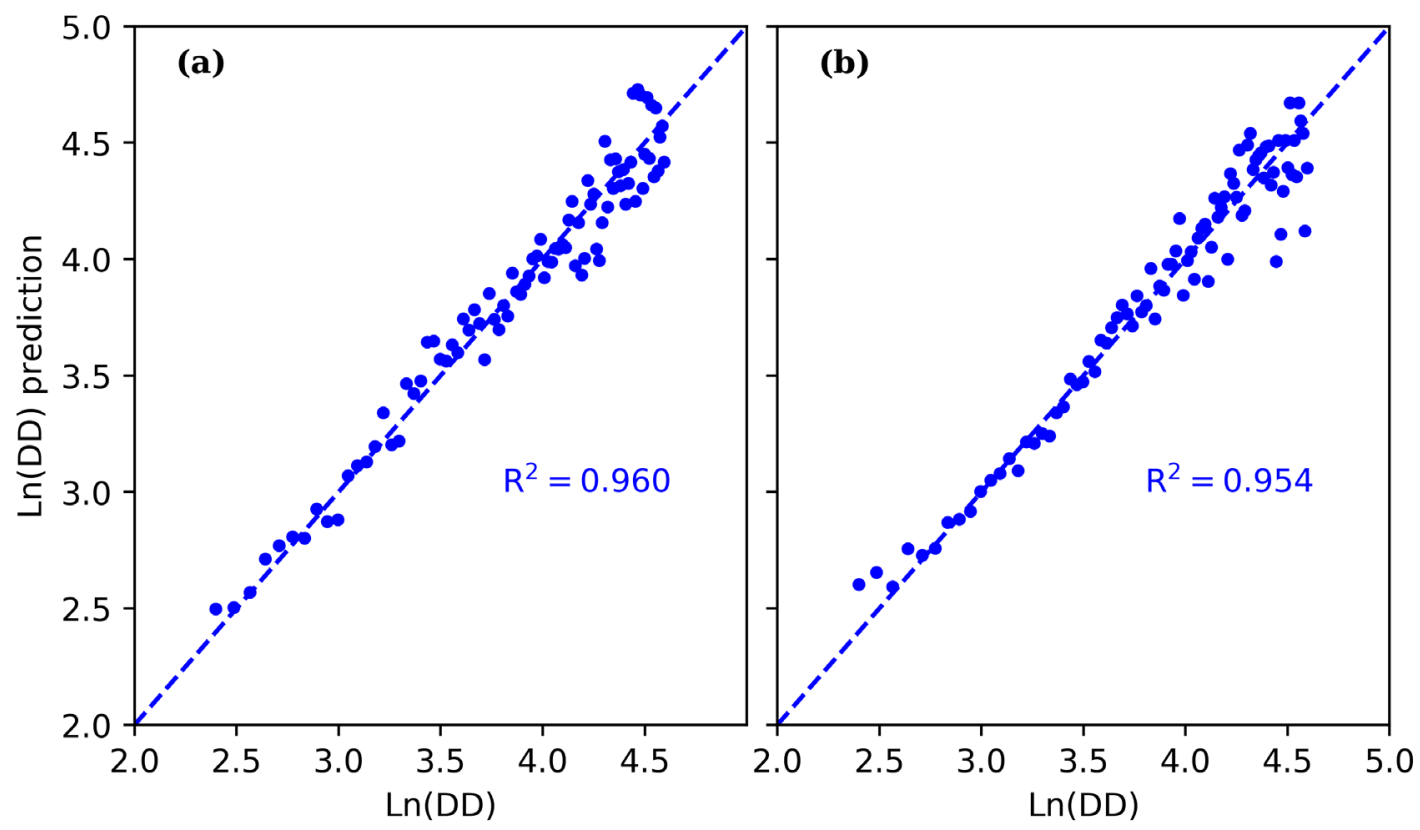

Fig. 8. Correlation between the actual and predicted damaged degrees (DD) for: (a)

2005; (b) 2013.

\section{DISCUSSION}

Over agricultural areas, there are many natural disasters that can cause great damage to crops, with the possibility to reduce grain production and destabilize food systems (Lesk et al., 2016).

Our aim of this study is to investigate the spatio-temporal varying flood disturbances at fine spatial scales due to the highly localized features of flooding. The proposed method is tested in the selected flood years of the Northeast China. During the selected flood years, the natural disasters that hit crop production for the study area were mainly extreme flood events. So the disturbance factor is simple and clean to some degree. And we have verified our disturbance 
detected results with spatial information of flood inundation via 2-D hydraulic model. It is likely, however, that there may be other disturbance factors that happen locally and impact crop growth even in flood years when the proposed method is applied in other cases. So the disturbance results need to be handled sensitively and should be interpreted cautiously. It is better to first get spatial information regarding flood characteristic and progress to help recognize floodimpacted areas. Recently, remote sensing imagery (e.g., Mohammadi et al., 2017) and 2-D hydraulic model (e.g., Chen et al., 2017) have provide the possibility for characterizing flood dynamics of large-scale floodplains. With the aid of these tools, the flood-impacted areas can be effectively identified and subsequently the disturbance detection results can be interpreted to obtain more reliable conclusions.

Previous studies have demonstrated that satellite-derived vegetation indexes are well correlated with ground biomass productivity (e.g., Hansen \& Schjoerring, 2003; Jin et al., 2013; Marshall \& Thenkabail, 2015). However, one limitation of using vegetation indexes to estimate biomass productivity is that they asymptotically saturate in high biomass (i.e., vegetation indexes become insensitive at high values of biomass productivity). Although EVI is more responsive to canopy structure variations and has improved sensitivity than other vegetation indexes (such as NDVI) in high biomass (Huete et al., 2002; Chen et al., 2006; Potithep et al., 2013), the saturation problem for EVI can't be completely solved (Lawrence et al., 2014). This problem may result in an underestimation of ecosystem productivity in dense biomass areas, which may influence the quantification of biomass productivity in high agricultural biomass areas during undisturbed years. But it has small influence on the quantification of agricultural biomass productivity when the crop areas are negatively by flood disturbances, which do not 
affect us to recognize these flood-affected area. Besides, crop yield depend on total crop biomass and the proportion of that biomass allocated to grain (Peng et al., 2004). Thus, the ratio of the EVI between the flood years and expected normal year cannot be viewed as the direct comparison on biomass productivity and actual crop yield with physical meaning and can be interpreted as a measure of flood impact, which just helps us understand the spatial-temporal characteristics of flood impact on crop growth.

Considering that no significant change has occurred in cropland areas in Northeast China during the study period, land use (cropland) change is not considered in our study. But given that it is impossible to completely avoid land use (cropland) change, one crop land cover data used for representing the conditions during 2000 to 2016 can still bring about some errors for the flooding disturbance detection results when compared with statistical area. And the GlobCover 2009 dataset used for extracting the cropland area has 70\% overall accuracy under 99\% confidence (Bontemps et al., 2011). The classification errors in GlobCover 2009 dataset deteriorate the accuracy of the flooding disturbance detection results. Thus, when the approach developed in this study is applied to other areas with significant land use change (e.g., transformation of cropland areas to built-up areas), the signal from land use change may seriously contaminate the detection results and the interference must be first eliminated. The high-precision cropland patterns may be examined in every year to extract the unalterable cropland areas. Applying the current approach only to these unalterable areas, the interference from land use change can be eliminated and the validity of the approach in detecting flood disturbances from natural variations can be ensured.

Corp growth requires water, nevertheless excess water that appears during submergence or 
waterlogging is detrimental or even lethal. Excess water causes crops to suffer the stresses of limited gas diffusion, soil nutrients effusion, mechanical damage, and increased susceptibility to diseases and pests (Setter et al., 1997; Ram et al., 1999). Previous studies have reported various adverse effects of flooding on crops, which varies with crop type, crop genotype, environmental conditions, growth stage when flooding occurs, flooding duration and severity. In Northeast China, the crop systems mainly include corn, rice, and soybean. Rice, unlike other crop plants, has good adaptive traits for tolerance of excess water stress (Nishiuchi et al., 2012).

Rice can form the longitudinal interconnection of gas spaces, which realizes internal aeration of shoot and roots (Colmer, 2003; Pedersen et al., 2009). Thus, it is expected that rice could be less affected by these flood events. However, growth and yield of most other crops would be impeded under the stress of excess water. For example, when soil moisture exceeds $80 \%$ of field capacity, maize growth and yield would be greatly reduced (Chen et al., 1988). Excess water can also result in injury or death to soybean. According to previous study, most soybean cultivars under the stress of continuously saturated soil averaged $40 \%$ less yields than furrowirrigated soybeans (Purcell et al., 1997; Rhine et al., 2010). So corn and soybean in Northeast China are expected to undergo negative effects of flooding. However, in this study, we do not have available crop pattern map as mask to distinguish crop types for such a large-scale areas, it is hard for us to survey or verify the responses of different crop types to flood. Further work are still needed to explore the different sensitivities of crop types to flooding.

Agriculture is one of the economic sectors that are most affected by extreme weather events, and doubtlessly most vulnerable due to the dependency of rural communities in developing regions. Extreme weather events are considered one of the most likely agricultural production 
risks over the next ten years (WEF, 2015). Flooding arising from intense rainfall may cause remarkable damage to crop production in specific sites. At the same time, water variability that intense rainfall associated with creates opportunities for water resource supply and storage, which can provide significant socio-ecological benefits for agricultural production. Since extreme precipitation events can be a natural and beneficial process, managing them is not about eliminating them, but rather minimizing risks and maximizing the benefit they provides. And due to strong spatial heterogeneity of flood impact, site-level knowledge on the field deployment of flood risk management is essential and flood risk management measures should be site-specific. Through the investigation of the spatio-temporal varying flood disturbances at fine spatial scales in this study, it is possible to provide policymakers with site-specific scientific information to develop effective flood risk management and adaptation interventions to protect the most vulnerable sites.

\section{CONCLUSIONS}

A simple, efficient, and scalable approach has been proposed and tested for detecting flood disturbances on crop production. The approach takes into consideration the interference of natural variations during the crop growth processes in processing flood impact signal. Two disturbance detection indices (DIs) are designed to track the disturbance process and integrated effects of flooding on crops on a pixel-by-pixel basis. The advantage of the new disturbance detection approach is illustrated through the provision of pixel-based spatial information on flood disturbed locations and extents, which is validated against the provincial statistics and is consistent with spatial characteristics of fluvial floods. The DIs successfully capture the response of crop systems to external disturbances, in terms of both positive and negative effects, 
providing a powerful tool for comprehensive flood disturbance detection and analysis. Using the detection results, stakeholders and decision-makers can locate the most vulnerable areas and develop proactive strategies in agriculture flood management.

It should be also noted that the integrated DI derived from the crop peak EVI can effectively detect the disturbances of floods happening before crop greenness reaches the peak value; however, it is less effective in assessing those flood events taking place during the crop's mature stages. Therefore, future work is still needed to develop effective methods for assessing flood impact on crop production after the crop peak greenness is passed.

\section{ACKNOWLEDGMENTS}

This work was supported by the National Basic Research Program of China (2015CB458900).

\section{REFERENCES}

Akbari, A., Samah, A. A., \& Daryabor, F. (2016). Raster-based derivation of a flood runoff susceptibility map using the revised runoff curve number $(\mathrm{CN})$ for the Kuantan watershed, Malaysia. Environmental Earth Sciences, 75(20), 1379.

Alemu, W. G., \& Henebry, G. M. (2013). Land surface phenologies and seasonalities using cool earthlight in mid-latitude croplands. Environmental Research Letters, 8(4), 045002.

Allen, M. R., \& Ingram, W. J. (2002). Constraints on future changes in climate and the hydrologic cycle. Nature, 419(6903), 224.

Arguello, M. N., Mason, R. E., Roberts, T. L., Subramanian, N., Acuña, A., \& Addison, C. K., et al. (2016). Performance of soft red winter wheat subjected to field soil waterlogging: grain yield and yield components. Field Crops Research, 194, 57-64.

Arino, O., Perez, J. J. R., Kalogirou, V., Bontemps, S., Defourny, P., \& Van Bogaert, E. (2012). Global land cover map for 2009 (GlobCover 2009).

Aryal, J. P., Sapkota, T. B., Stirling, C. M., Jat, M. L., Jat, H. S., \& Rai, M., et al. (2016). Conservation agriculture-based wheat production better copes with extreme climate events than conventional tillage-based systems: A case of untimely excess rainfall in Haryana, India. Agriculture, Ecosystems \& Environment, 233, 325-335.

Beckerreshef, I., Vermote, E., Lindeman, M., \& Justice, C. (2010). A generalized regression-based model for forecasting winter wheat yields in Kansas and Ukraine using MODIS data. Remote Sensing of Environment, 114(6), 1312-1323. 
Beeri, O., \& Peled, A. (2009). Geographical model for precise agriculture monitoring with realtime remote sensing. ISPRS Journal of Photogrammetry and Remote Sensing, 64(1), 47-54.

Bernardes, T., Moreira, M. A., Adami, M., \& Giarolla, A. (2012). Monitoring biennial bearing effect on coffee yield using MODIS remote sensing imagery. Remote Sensing, 4(9), 3760-3763.

Bolton, D. K., \& Friedl, M. A. (2013). Forecasting crop yield using remotely sensed vegetation indices and crop phenology metrics. Agricultural \& Forest Meteorology, 173(2), 74-84.

Bontemps, S., Defourny, P., Bogaert, E. V., Arino, O., Kalogirou, V., \& Perez, J. R. (2011). GLOBCOVER 2009-Products description and validation report.

Brindha, K., \& Pavelic, P. (2016). Identifying priority watersheds to mitigate flood and drought impacts by novel conjunctive water use management. Environmental Earth Sciences, 75(5), 1-17.

Chen, C., Qian, C., Deng, A., \& Zhang, W. (2012). Progressive and active adaptations of cropping system to climate change in Northeast China. European Journal of Agronomy, 38, 94-103.

Chen, G., Zhao, S., Yang, H., \& He, C. (1988). Studies on waterlogging of corn and protection measures I. Effects of waterlogging on bud bursting stage on the emergence and early growth of seedling of corn. Acta Agriculture Boreali-sinica, 3, 12-17.

Chen, H., Liang, Z., Liu, Y., Liang, Q., \& Xie, S. (2017). Integrated Remote Sensing Imagery and Two-dimensional Hydraulic Modeling Approach for Impact Evaluation of Flood on Crop Yields. Journal of Hydrology, 553, 262-275.

Chen, P, Fedosejevs, G., Tiscareno-Lopez, M., \& Arnold, J. (2006). Assessment of MODIS-EVI, MODIS-NDVI and VEGETATION-NDVI composite data using agricultural measurements: an example at corn fields in western Mexico. Environmental monitoring and assessment, 119(1-3), 69-82.

China National Commission for Disaster Reduction. (2005a). National disaster records in July 2005. Disaster Reduction in China, (9), 61-66. (In Chinese)

China National Commission for Disaster Reduction. (2005b). National disaster records in August 2005. Disaster Reduction in China, (9), 61-66. (In Chinese)

Cobon, D. H., Ewai, M., Inape, K., \& Bourke, R. M. (2016). Food shortages are associated with droughts, floods, frosts and ENSO in Papua New Guinea. Agricultural Systems, 145, 150-164.

Colmer, T. D. (2003). Long-distance transport of gases in plants: a perspective on internal aeration and radial oxygen loss from roots. Plant, Cell \& Environment, 26(1), 17-36.

Cong, D., Zhao, S., Chen, C., \& Duan, Z. (2017). Characterization of droughts during 2001-2014 based on remote sensing: a case study of northeast china. Ecological Informatics, 39, 56-67.

Di, L., Eugene, G. Y., Kang, L., Shrestha, R., \& BAI, Y. Q. (2017). RF-CLASS: A remote-sensingbased flood crop loss assessment cyber-service system for supporting crop statistics and insurance decision-making. Journal of Integrative Agriculture, 16(2), 408-423.

Didan, K. (2015). MOD13Q1 MODIS/Terra vegetation indices 16-day L3 global 250m SIN grid V006. NASA EOSDIS Land Processes DAAC.

Didan, K., Barreto-Munoz, A., Solano, R., \& Huete, A. (2015). MODIS Vegetation Index User's Guide (MOD13 Series).1-35 https://vip.arizona.edu/documents/MODIS/MODIS_VI_UsersGuide_June_2015_C6.pdf

Donat, M. G., Lowry, A. L., Alexander, L. V., O’Gorman, P. A., \& Maher, N. (2016). More 
extreme precipitation in the world's dry and wet regions. Nature Climate Change, 6(5).

Duan, T., Chapman, S. C., Guo, Y., \& Zheng, B. (2017). Dynamic monitoring of NDVI in wheat agronomy and breeding trials using an unmanned aerial vehicle. Field Crops Research, 210, 71-80.

Džubáková, K., Molnar, P., Schindler, K., \& Trizna, M. (2015). Monitoring of riparian vegetation response to flood disturbances using terrestrial photography. Hydrology \& Earth System Sciences, 19(3), 195-208.

Eriyagama, Nishadi; Muthuwatta, Lal; Thilakarathne, Madusanka. 2014. Minimizing flood damage and augmenting dry season water availability: prospects for floodwater harvesting and underground storage in Sri Lanka. Proceedings of the Disaster Management Conference. 379-381.

Farr, T. G., Rosen, P. A., Caro, E., Crippen, R., Duren, R., \& Hensley, S., et al. (2007). The shuttle radar topography mission. Reviews of Geophysics, 1(2), 361.

Franke, J., \& Menz, G. (2007). Multi-temporal wheat disease detection by multi-spectral remote sensing. Precision Agriculture, 8(3), 161-172.

Garcia, R. A., Cabeza, M., Rahbek, C., \& Araújo, M. B. (2014). Multiple dimensions of climate change and their implications for biodiversity. Science, 344(6183), 1247579.

Garssen, A. G., Baattrup-Pedersen, A., Voesenek, L. A., Verhoeven, J. T., \& Soons, M. B. (2015). Riparian plant community responses to increased flooding: a meta-analysis. Global change biology, 21(8), 2881-2890.

Gigović, L., Pamučar, D., Bajić, Z., \& Drobnjak, S. (2017). Application of GIS-Interval Rough AHP Methodology for Flood Hazard Mapping in Urban Areas. Water, 9(6), 360.

Gourdji, S., Läderach, P., Valle, A. M., Martinez, C. Z., \& Lobell, D. B. (2015). Historical climate trends, deforestation, and maize and bean yields in Nicaragua. Agricultural and Forest Meteorology, 200, 270-281.

Groten, S. M. E., (1993). NDVI-crop monitoring and early yield assessment of Burkina Faso. International Journal of Remote Sensing, 14(8), 1495-1515.

Guo, P., Huang, G. H., \& Li, Y. P. (2010). An inexact fuzzy-chance-constrained two-stage mixedinteger linear programming approach for flood diversion planning under multiple uncertainties. Advances in Water Resources, 33(1), 81-91.

Haas, E. M., Bartholomé, E., \& Combal, B. (2009). Time series analysis of optical remote sensing data for the mapping of temporary surface water bodies in sub-Saharan western Africa. Journal of Hydrology, 370(1-4), 52-63.

Hansen, P. M., \& Schjoerring, J. K. (2003). Reflectance measurement of canopy biomass and nitrogen status in wheat crops using normalized difference vegetation indices and partial least squares regression. Remote sensing of environment, 86(4), 542-553.

Hoerl, A. E., \& Kennard, R. W. (1970). Ridge regression: Biased estimation for nonorthogonal problems. Technometrics, 12(1), 55-67.

Huete, A., Didan, K., Miura, T., Rodriguez, E. P., Gao, X., \& Ferreira, L. G. (2002). Overview of the radiometric and biophysical performance of the MODIS vegetation indices. Remote sensing of environment, 83(1), 195-213.

Huete, A., Justice, C., \& Van Leeuwen, W. (1999). MODIS vegetation index (MOD13). Algorithm 
theoretical basis document, 3, 213.

Jafarzadegan, K., \& Merwade, V. (2017). A DEM-based approach for large-scale floodplain mapping in ungauged watersheds. Journal of Hydrology, 550, 650-662.

Jgpw, C., \& Hjcvan, L. (1996). Combined use of optical and microwave remote sensing data for crop growth monitoring. Remote Sensing of Environment, 56(1), 42-51.

Jin, X., Diao, W., Xiao, C., Wang, F., Chen, B., Wang, K., \& Li, S. (2013). Estimation of wheat agronomic parameters using new spectral indices. PLoS One, 8(8), e72736.

Kadari, A., Mekala, S. R., Wagner, N., Malan, D., Köth, J., \& Doll, K., et al. (2011). Human contribution to more-intense precipitation extremes. Nature, 470(7334), 378.

Kazakis, N., Kougias, I., \& Patsialis, T. (2015). Assessment of flood hazard areas at a regional scale using an index-based approach and analytical hierarchy process: application in Rhodope-Evros region, Greece. Science of the Total Environment, 538, 555-563.

Kent, R. J., \& Johnson, D. E. (2001). Influence of flood depth and duration on growth of lowland rice weeds, Cote d'Ivoire. Crop Protection, 20(8), 691-694.

Kenyon, W., Hill, G., \& Shannon, P. (2008). Scoping the role of agriculture in sustainable flood management. Land Use Policy, 25(3), 351-360.

Kotera, A., Nagano, T., Hanittinan, P., \& Koontanakulvong, S. (2016). Assessing the degree of flood damage to rice crops in the Chao Phraya delta, Thailand, using MODIS satellite imaging. Paddy and Water Environment, 14(1), 1-10.

Lawrence, H., Wigneron, J. P., Richaume, P., Novello, N., Grant, J., \& Mialon, A., et al. (2014). Comparison between SMOS Vegetation Optical Depth products and MODIS vegetation indices over crop zones of the USA. Remote Sensing of Environment, 140(1), 396-406.

Lehner, B., Verdin, K., \& Jarvis, A. (2008). New global hydrography derived from spaceborne elevation data. Eos, Transactions American Geophysical Union, 89(10), 93-94.

Lesk, C., Rowhani, P., \& Ramankutty, N. (2016). Influence of extreme weather disasters on global crop production. Nature, 529(7584), 84-87.

Li, S., Du, X., Tong, Y., Chi, Y., Lu, Y., \& Wang, Z. (2011). Experiment study on promotion techniques for rain \& flood water harvesting through underground storage. Hydrogeology \& Engineering Geology. 38(5), 13-19.

Li, S., Tompkins, A. M., Lin, E., \& Ju, H. (2016). Simulating the impact of flooding on wheat yield-Case study in East China. Agricultural and Forest Meteorology, 216, 221-231.

Liu, B. C., Liu, Y., Yang, F., Yang, X. J., \& Bai, W. (2016). Estimating crop water deficit during maize potential growth period and climatic sensitivity analysis in northeast china, 1961-2010. Journal of Agricultural Science, 155(3), 394-406.

Liu, J., Kuang, W., Zhang, Z., Xu, X., Qin, Y., Ning, J., Zhou, W., Zhang, S., Li, R., Yan, C., Wu, S., Shi, X., Jiang, N., Yu, D., Pan, X., \& Chi, W. (2014). Spatiotemporal characteristics, patterns, and causes of land-use changes in China since the late 1980s. Journal of Geographical Sciences, 24(2), 195-210.

Lu, J., Carbone, G. J., \& Gao, P. (2017). Detrending crop yield data for spatial visualization of drought impacts in the United States, 1895-2014. Agricultural and Forest Meteorology, 237, 196-208. 
Lobell, D. B., Torney, A., \& Field, C. B. (2011). Climate extremes in California agriculture. Climatic Change, 109(1), 355-363.

Marshall, M., \& Thenkabail, P. (2015). Advantage of hyperspectral EO-1 Hyperion over multispectral IKONOS, GeoEye-1, WorldView-2, Landsat ETM+, and MODIS vegetation indices in crop biomass estimation. ISPRS Journal of Photogrammetry and Remote Sensing, 108, 205-218.

Merz, B., Aerts, J., Arnbjergnielsen, K., Baldi, M., Becker, A., \& Bichet, A., et al. (2014). Floods and climate: emerging perspectives for flood risk assessment and management. Natural Hazards \& Earth System Sciences, 2(2), 1559-1612.

Midi, H., Sarkar, S. K., \& Rana, S. (2010). Collinearity diagnostics of binary logistic regression model. Journal of Interdisciplinary Mathematics, 13(3), 253-267.

Mildrexler, D. J., Zhao, M., \& Running, S. W. (2009). Testing a MODIS global disturbance index across North America. Remote Sensing of Environment, 113(10), 2103-2117.

Mildrexler, D. J., Zhao, M., Heinsch, F. A., \& Running, S. W. (2007). A new satellite-based methodology for continental-scale disturbance detection. Ecological Applications, 17(1), 235-250.

Moges, Y. (2004). Water harvesting techniques: Training and construction manual. Consultancy sub-report number 2. Tropical Forestry.

Mohammadi, A., Costelloe, J. F., \& Ryu, D. (2017). Application of time series of remotely sensed normalized difference water, vegetation and moisture indices in characterizing flood dynamics of largescale arid zone floodplains. Remote Sensing of Environment, 190, 70-82.

Nishiuchi, S., Yamauchi, T., Takahashi, H., Kotula, L., \& Nakazono, M. (2012). Mechanisms for coping with submergence and waterlogging in rice. Rice, 5(1), 2.

Ogilvie, A., Belaud, G., Delenne, C., Bailly, J. S., Bader, J. C., \& Oleksiak, A., et al. (2015). Decadal monitoring of the Niger Inner Delta flood dynamics using MODIS optical data. Journal of Hydrology, 523, 368-383.

Pantaleoni, E., Engel, B. A., \& Johannsen, C. J. (2007). Identifying agricultural flood damage using Landsat imagery. Precision Agriculture, 8(1), 27-36.

Pavelic, P., Srisuk, K., Saraphirom, P., Nadee, S., Pholkern, K., \& Chusanathas, S., et al. (2012). Balancing-out floods and droughts: opportunities to utilize floodwater harvesting and groundwater storage for agricultural development in Thailand. Journal of Hydrology, 470-471(4), 55-64.

Pedersen, O., Rich, S. M., \& Colmer, T. D. (2009). Surviving floods: leaf gas films improve O2 and $\mathrm{CO} 2$ exchange, root aeration, and growth of completely submerged rice. The Plant Journal, 58(1), 147-156.

Peng, S., Huang, J., Sheehy, J. E., Laza, R. C., Visperas, R. M., \& Zhong, X., et al. (2004). Rice yields decline with higher night temperature from global warming. Proceedings of the National Academy of Sciences, 101(27), 9971-9975.

Piao, M., Hongyan, Z., Zhao, J., \& Guo, X. (2014). The influence of drought and flood Disasters on rice NDVI in summer. In IOP Conference Series: Earth and Environmental Science, 17, 682-691.

Potithep, S., Nagai, S., Nasahara, K. N., Muraoka, H., \& Suzuki, R. (2013). Two separate periods of the LAI-VIs relationships using in situ measurements in a deciduous broadleaf forest. Agricultural and forest meteorology, 169, 148-155. 

impacts of key adverse weather events on the field - grown vegetable yield variability in the Czech Republic from 1961 to 2014. International Journal of Climatology, 37(3), 1648-1664.

Purcell, L. C., Vories, E. D., Counce, P. A., \& King, C. A. (1997). Soybean growth and yield response to saturated soil culture in a temperate environment. Field crops research, 49(2-3), 205-213.

Ram, P. C., Singh, A. K., Singh, B. B., Singh, V. K., Singh, H. P., Setter, T. L., Singh, V. P. and Singh, R. K. (1999). Environmental characterization of floodwater in eastern India: relevance to submergence tolerance of lowland rice. Experimental Agriculture 35(2):141-152.

Rasmussen, M. S. (1992). Assessment of millet yields and production in northern Burkina Faso using integrated NDVI from the AVHRR. International Journal of Remote Sensing, 13(18), 3431-3442.

Rembold, F., Atzberger, C., Savin, I., \& Rojas, O. (2013). Using low resolution satellite imagery for yield prediction and yield anomaly detection. Remote Sensing, 5(4), 1704-1733.

Rhine, M. D., Stevens, G., Shannon, G., Wrather, A., \& Sleper, D. (2010). Yield and nutritional responses to waterlogging of soybean cultivars. Irrigation science, 28(2), 135-142.

Rocha, A. V., \& Shaver, G. R. (2009). Advantages of a two band EVI calculated from solar and photosynthetically active radiation fluxes. Agricultural \& Forest Meteorology, 149(9), 1560-1563.

Rosenzweig, C., Tubiello, F. N., Goldberg, R., Mills, E., \& Bloomfield, J. (2002). Increased crop damage in the US from excess precipitation under climate change. Global Environmental Change, 12(3), 197-202.

Saher, F. N., Nasly, M. A., Kadir, T. A. A., Yahaya, N. K. E. M., \& Wan Ishak, W. M. F. (2015). Managing flood water of hill torrents as potential source for irrigation. Journal of Flood Risk Management, 8(1), 87-95.

Sakamoto, T., Van Nguyen, N., Kotera, A., Ohno, H., Ishitsuka, N., \& Yokozawa, M. (2007). Detecting temporal changes in the extent of annual flooding within the Cambodia and the Vietnamese Mekong Delta from MODIS time-series imagery. Remote sensing of environment, 109(3), 295-313.

Sakamoto, T., Yokozawa, M., Toritani, H., Shibayama, M., Ishitsuka, N., \& Ohno, H. (2005). A crop phenology detection method using time-series MODIS data. Remote sensing of environment, 96(3), 366-374.

Samantaray, D., Chatterjee, C., Singh, R., Gupta, P. K., \& Panigrahy, S. (2015). Flood risk modeling for optimal rice planning for delta region of Mahanadi river basin in India. Natural Hazards, 76(1), 347-372.

Schiermeier, Q. (2011). Increased flood risk linked to global warming. Nature, 470(7334), 316.

Seddon, A. W. R., Maciasfauria, M., Long, P. R., Benz, D., \& Willis, K. J. (2016). Sensitivity of global terrestrial ecosystems to climate variability. Nature, 531(7593), 229.

Setter, T. L., Ellis, M., Laureles, E. V., Ella, E. S., Senadhira, D. , \& Mishra, S. B., et al. (1997). Physiology and genetics of submergence tolerance in rice. Annals of Botany, 79, 67-77.

Shi, H., Li, L., Eamus, D., Huete, A., Cleverly, J., \& Tian, X., et al. (2017). Assessing the ability of MODIS EVI to estimate terrestrial ecosystem gross primary production of multiple land cover types. Ecological Indicators, 72, 153-164.

Simpsona, J. R., \& Montgomery, D. C. (1996). A biased-robust regression technique for the 
combined outlier-multicollinearity problem. Journal of Statistical Computation and Simulation, 56(1), $1-22$.

Shrestha, R., Di, L., Eugene, G. Y., Kang, L., SHAO, Y. Z., \& BAI, Y. Q. (2017). Regression model to estimate flood impact on corn yield using MODIS NDVI and USDA cropland data layer. Journal of Integrative Agriculture, 16(2), 398-407.

Son, N. T., Chen, C. F., Chen, C. R., Minh, V. Q., \& Trung, N. H. (2014). A comparative analysis of multitemporal MODIS EVI and NDVI data for large-scale rice yield estimation. Agricultural \& Forest Meteorology, 197(6), 52-64.

Subash, N., Singh, S. S., \& Priya, N. (2011). Extreme rainfall indices and its impact on rice productivity - a case study over sub-humid climatic environment. Agricultural water management, 98(9), 1373-1387.

Taylor, C. M., Belušić, D., Guichard, F., Parker, D. J., Vischel, T., \& Bock, O., et al. (2017). Frequency of extreme Sahelian storms tripled since 1982 in satellite observations. Nature, 544(7651), 475-478.

Tehrany, M. S., Pradhan, B., Mansor, S., \& Ahmad, N. (2015). Flood susceptibility assessment using GIS-based support vector machine model with different kernel types. Catena, 125(125), 91-101.

Thornton, P. K., Ericksen, P. J., Herrero, M., \& Challinor, A. J. (2014). Climate variability and vulnerability to climate change: a review. Global Change Biology, 20(11), 3313-3328.

Wang, X., Deng, Z., Zhang, W., Meng, Z., Chang, X., \& Lv, M. (2017). Effect of Waterlogging Duration at Different Growth Stages on the Growth, Yield and Quality of Cotton. Plos One, 12(1), e0169029.

WEF (World Economic Forum). 2015. Global Risks Report 2015. 10th edition. Geneva, WEF. reports.weforum.org/global-risks-2015/.

Xiao, F.J., \& Xu, L.Y. (2006). Characteristics of weather and climate and main meteorological disasters in China in 2005. Meteorological Monthly, 32(4), 78-83. (In Chinese)

Xu, M., Ma, H., Zeng, L., Cheng, Y., Lu, G., \& Xu, J., et al. (2015). The effect of waterlogging on yield and seed quality at the early flowering stage in Brassica Napus, L. Field Crops Research, 180, 238-245.

Yang, J., Huo, Z., Wu, L., Wang, T., \& Zhang, G. (2016). Indicator-based evaluation of spatiotemporal characteristics of rice flood in Southwest China. Agriculture, Ecosystems \& Environment, 230, 221-230.

Yang, X., Lin, E., Ma, S., Ju, H., Guo, L., \& Xiong, W., et al. (2007). Adaptation of agriculture to warming in northeast china. Climatic Change, 84(1), 45-58.

Zhang, J., Feng, L., \& Yao, F. (2014). Improved maize cultivated area estimation over a large scale combining MODIS-EVI time series data and crop phenological information. ISPRS Journal of Photogrammetry \& Remote Sensing, 94(94), 102-113.

Zhang, Q., Gu, X., Singh, V. P., Kong, D., \& Chen, X. (2015). Spatiotemporal behavior of floods and droughts and their impacts on agriculture in China. Global \& Planetary Change, 131, 63-72.

Zhang, Q., Gu, X., Singh, V. P., Liu, L., \& Kong, D. (2016). Flood-induced agricultural loss across 
China and impacts from climate indices. Global \& Planetary Change, 139, 31-43.

Zhang, X., \& Zhang, Q. (2016). Monitoring interannual variation in global crop yield using longterm AVHRR and MODIS observations. ISPRS Journal of Photogrammetry \& Remote Sensing, 114, 870 191-205.

871 Zhang, X., Friedl, M. A., Schaaf, C. B., Strahler, A. H., Hodges, J. C. F., \& Gao, F., et al. (2003).

872 Monitoring vegetation phenology using MODIS. Remote sensing of environment, 84(3), 471-475.

873 Zhang, Y., Chen, Y., Lu, H., Kong, X., Dai, J., \& Li, Z., et al. (2016). Growth, lint yield and

874 changes in physiological attributes of cotton under temporal waterlogging. Field Crops Research, 194, 875 83-93.

876 Zhu, J., Huang, G., Wang, X., Cheng, G., \& Wu, Y. (2017). High-resolution projections of mean and 877 extreme precipitations over China through PRECIS under RCPs. Climate Dynamics, 50, 1-24. 